\title{
Metal Emulsion in Sn Alloy/oxide System by Bottom Gas Injection
}

\author{
Jiang $\mathrm{LIU}^{1{ }^{1) *}}$ Sun-joong $\mathrm{KIM}^{21}{ }^{2)} \mathrm{Xu} \mathrm{GAO},{ }^{3)}$ Shigeru UEDA ${ }^{3)}$ and Shin-ya KITAMURA ${ }^{3)}$ \\ 1) Graduate School of Engineering, Tohoku University, 6-6 Aoba, Aramaki, Aoba-ku, Sendai, 980-8579 Japan. \\ 2) Institute of Multidisciplinary Research for Advanced Materials, Tohoku University. Now Department of Materials Science \\ and Engineering, College of Engineering, Chosun University 309, Pilmun-daero, Dong-gu, Gwangju, 61452 Korea. \\ 3) Institute of Multidisciplinary Research for Advanced Materials, Tohoku University, 2-1-1 Katahira, Aoba-ku, Sendai, 980- \\ 8055 Japan.
}

(Received on September 28, 2016; accepted on December 5, 2016)

\begin{abstract}
A metal emulsion is formed by the passage of gas bubbles through the interface between the metal phase and the slag phase in the steelmaking process. Emulsified metal droplets have great potential to improve the chemical reaction efficiency during motion in bulk slag. Several studies have focused on the formation mechanism of metal droplets and on the influence of the physical properties of the system on this mechanism. In this study, Sn alloy and sodium tetraborate were used to simulate molten steel and slag, respectively. Gas bubbles were introduced from the bottom of a molten metal bath at various gas flow rates. Slag containing metal droplets at the center of the slag phase was sampled, and the metal droplets were extracted by the dissolution of the oxide in a solvent. The number and diameter of the droplets were measured using a digital microscope. Under the same experimental conditions, the number of metal droplets in the oxide system was smaller but their size was larger than those in a previously investigated Sn alloy/chloride system. In both the systems, the total mass of metal droplets formed by a single bubble increased with an increase in the volume of the gas bubble, and when the volume of the gas bubble was small, the total mass of droplets in the oxide system was smaller than that in the chloride system. The sedimentation rate and coefficient in the oxide system were lower than those in the chloride system.
\end{abstract}

KEY WORDS: metal emulsion; metal droplets; gas bubble; formation rate; sedimentation rate.

\section{Introduction}

An emulsion is formed when the interface of two immiscible liquids is disturbed by the input of energy, e.g., by the passage of gas bubbles or mechanical agitation. Emulsified droplets dispersed in another phase have great potential to improve the mass and heat transfer because of the increased interfacial area. Therefore, the efficiency of a chemical reaction between two liquids can be increased by the emulsification process. A metal emulsion is often observed between molten steel and slag in the steelmaking process.

Upon passage of gas bubbles introduced from the bottom of a molten metal bath through the interface between the metal and slag phase, the metal phase entrains into the slag phase and ruptures into metal droplets. The larger of these droplets settle down to the metal phase rapidly owing to the gravitational force being larger than the buoyancy force and the viscous drag force. However, smaller droplets remain in bulk slag for a long time without sedimentation and cause metal loss, which has been reported to be approximately $1 \%-3.7 \%$ in the actual process. ${ }^{1,2)}$ Hence, it is of great importance to clarify the formation mechanism and motion of a metal emulsion in the slag phase and also to determine

* Corresponding author: E-mail: liujiangdubu@gmail.com DOI: http://dx.doi.org/10.2355/isijinternational.ISIJINT-2016-573 the effects of physical properties of the system on the formation mechanism and motion.

Over the decades, several studies have been conducted using various liquid/liquid systems. Three main formation mechanisms, ${ }^{3-8)}$ classified according to gas bubble movement, have been found.

(1) When a gas bubble reaches the interface, a metal film of a certain thickness covers the bubble and forms a dome. As the gas bubble rises, the film becomes thin and finally ruptures into droplets.

(2) When a gas bubble passes through the interface, a metal column of a certain width is formed under the gas bubble, which is covered by the metal film. The metal column lengthens as the bubble moves upward. At a certain height, the column disintegrates into metal droplets.

(3) When some succeeding bubbles reach the interface before the previous bubble is detached from the interface, these bubbles combine and form an elongated large dome. The bubbles move upward together, and at some height, the connected metal film breaks into droplets.

The influence of physical properties of the system on the formation and sedimentation of a metal emulsion has been studied. For example, Reiter and Schwerdtfeger ${ }^{7)}$ observed the emulsion behavior in a cold liquid/liquid system, e.g., water/mercury and cyclohexane/water systems, by using a high-speed camera. They found that a metal jet (column) 
was formed even by a small gas bubble in a cyclohexane/ water system, which had lower interfacial tension and a smaller density difference; however, a metal column was formed only by a large gas bubble in a water/mercury system, which had higher interfacial tension and a larger density difference. The average size of the metal droplet was relatively larger in the water/oil system than that in the water/mercury system. Lin and Guthrir ${ }^{8)}$ quantified the volume of droplets entrained into the upper phase of some cold system. They observed that an increase in the viscosity of the upper phase and a decrease in the density of the lower phase enhanced the formation of droplets. However, the height of the molten bath had no significant effect on the droplet formation rate. Han and Holappa ${ }^{9)}$ observed the formation of steel droplets by an in-situ X-ray transmission technique. They found that the total mass of droplets attained a local maximum at a certain gas bubble size, and it decreased with an increase in the surface tension.

The physical properties of materials used in a cold model are greatly different from those of materials used in the actual process. On the other hand, although steel droplets can be observed by the X-ray technique, it is impossible to measure the size distribution because of the low resolution of the X-ray instrument. Previously, Poggi et al. ${ }^{10)}$ performed experiments using $\mathrm{Pb}$ and a molten salt system. In this system, the suspended metal droplets could be separated because the molten salt was soluble in water. Using this technique, Song et al. ${ }^{11-13)}$ investigated the emulsion phenomena of low-melting-point metals $(\mathrm{Pb}, \mathrm{Al}$, and $\mathrm{Sn}$ alloy) and of the $\mathrm{KCl}-\mathrm{NaCl}-\mathrm{LiCl}$ molten salt system. In all these studies, gas was introduced from the bottom of the molten metal bath and the salt was sampled at certain time intervals. The emulsified metal droplets were extracted by water treatment, and their size distribution was measured. In addition, the formation behaviors of the bubbles and droplets in the salt phase were observed using a high-speed camera. Direct measurement of the size distribution of metal droplets by the collection of every droplet in the salt sample was a significant achievement. However, it was not possible to understand the emulsion behavior in a steel/slag system, because of the distinct differences in the physical properties of the two systems, especially the viscosities of the upper phases. Therefore, in the present study, oxide was used instead of chloride in order to simulate the emulsion formation behavior of a molten steel/slag system by gas injection.

\section{Experiment}

In this experiment, Sn alloy (90.5 mass \% Sn, 7.5 mass\% $\mathrm{Sb}$, and 2.0 mass $\% \mathrm{Cu}$ ) and sodium tetraborate $\left(\mathrm{Na}_{2} \mathrm{~B}_{4} \mathrm{O}_{7}\right)$ were employed to imitate the molten steel and slag, respectively, for the following reasons: ${ }^{15)}$ (1) the separation of metal droplets can be achieved as the oxide dissolves into a water-glycerin mixed solution; (2) no chemical reactions occur between this oxide and the Sn alloy; (3) bubbling behavior can be observed as this oxide is transparent; and (4) at the experimental temperature, the physical properties of this system are close to those of the steel/slag system, as presented in Table 1. ${ }^{16-19)}$ To enable comparison of our findings with those of a previous study using a Sn alloy/chloride system, ${ }^{3)}$ the same experimental conditions as those in the previous study were adopted in the present study, including the sampling method, height of each liquid phase, gas flow rate, and composition of the Sn alloy. ${ }^{3)}$

\subsection{Experimental Setup}

The experiment was performed in a resistance furnace at $1093 \mathrm{~K}$ as shown in Fig. 1. Given the chemical inertness of $\mathrm{MgO}$ to $\mathrm{Sn}$ alloy and sodium tetraborate at the experimental temperature, a cylindrical high-purity $\mathrm{MgO}$ crucible was used as a container with an inner diameter of $60 \mathrm{~mm}$ and height of $190 \mathrm{~mm}$. The heights of the charged oxide and Sn alloy were $70 \mathrm{~mm}$ and $60 \mathrm{~mm}$, respectively. Ar with 3 vol $\% \mathrm{H}_{2}$ was employed to prevent the oxidation of metal and injected from the bottom center of the molten metal bath through a single-hole quartz nozzle with an inner diameter of $1 \mathrm{~mm}$. The gas flow rate was adjusted using a mass flow controller, where the flow rate was adjustable from $25 \mathrm{NmL} / \mathrm{min}$ to $500 \mathrm{NmL} / \mathrm{min}$. To keep the temperature of the molten bath stable even at a high gas flow rate, the gas was preheated by passing a bent glass tube through the furnace. The part of the gas tube immersed in the molten slag was covered with an external $\mathrm{MgO}$ tube to prevent the

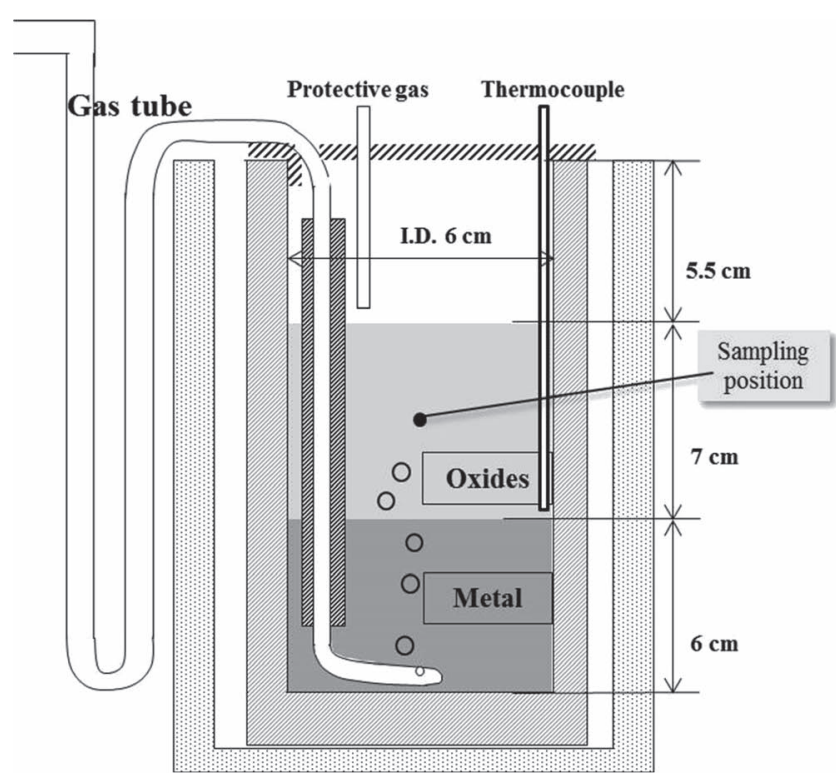

Fig. 1. Schematic diagram of setup of bubbling experiment.

Table 1. Properties of experiment materials and actual steel/slag system.

\begin{tabular}{cccccc}
\hline System (lower/upper) & $\begin{array}{c}\text { Temperature } \\
{\left[\mathrm{K}\left({ }^{\circ} \mathrm{C}\right)\right]}\end{array}$ & $\begin{array}{c}\text { Density of upper } \\
\text { phase }\left[\mathrm{kg} / \mathrm{m}^{3}\right]\end{array}$ & $\begin{array}{c}\text { Density ratio of } \\
\text { upper/lower phase }\end{array}$ & $\begin{array}{c}\text { Viscosity of upper } \\
\text { phase }[\mathrm{Pa} \cdot \mathrm{s}]\end{array}$ & $\begin{array}{c}\text { Interfacial } \\
\text { tension }[\mathrm{N} / \mathrm{m}]\end{array}$ \\
\hline $\mathrm{Sn}$ alloy/ $\mathrm{Na}_{2} \mathrm{~B}_{4} \mathrm{O}_{7}$ & $1093(820)$ & 2086 & 0.318 & 1.23 & 0.5168 \\
Sn alloy/Chloride & $723(450)$ & 1541 & 0.226 & 0.00275 & 0.555 \\
Actual process (steel/slag) & $1873(1600)$ & $\approx 2600$ & 0.366 & $0.1-1$ & $0.3-1.5$ \\
\hline
\end{tabular}


dissolution of quartz into the oxide phase. The same gas was introduced from the top of the slag surface by means of a $\mathrm{MgO}$ tube at $400 \mathrm{NmL} / \mathrm{min}$ to maintain the atmosphere. A thermocouple was inserted at the interface between the molten metal and the oxide during bubbling. The system was covered with a refractory lid having a hole in the center for the purpose of sampling. Oxides with emulsified metal droplets were sampled at the center position of the oxide bath by using a $\mathrm{MgO}$ tube with an inner diameter of $4 \mathrm{~mm}$, as this position represents the average behavior, as elucidated by a previous study. ${ }^{3)}$ A syringe was connected to this $\mathrm{MgO}$ tube for extraction of the sample.

\subsection{Experimental Procedure}

Approximately $413 \mathrm{~g}$ of sodium tetraborate $\left(\mathrm{Na}_{2} \mathrm{~B}_{4} \mathrm{O}_{7}\right)$ was added to the $\mathrm{MgO}$ crucible at room temperature and heated to $1093 \mathrm{~K}$. Metallic Sn alloy nuggets, weighing $1112 \mathrm{~g}$ in total, were then charged sequentially. After melting of both phases, the gas tube and thermocouple were inserted and kept in the molten bath for several minutes until the temperature became stable. Mixed gas was introduced simultaneously from both the bottom and top of the system. Approximately $3 \mathrm{~g}$ of the sample was extracted at certain time intervals during bubbling. At $120 \mathrm{~min}$, gas flow from the bottom was stopped but the sampling was continued at the same time intervals for another $120 \mathrm{~min}$ in order to investigate the sedimentation rate of the metal droplets. The samples were cooled on a copper plate rapidly and inserted into a solvent composed of a mixture of ion-exchanged water and glycerin at a volume ratio of 1:1 at approximately $323 \mathrm{~K}$. After the $\mathrm{Na}_{2} \mathrm{~B}_{4} \mathrm{O}_{7}$ dissolved in the solvent, Sn droplets could be separated by filtration.

The number and diameter of the metal droplets on the filter paper were analyzed using a digital microscope. In addition, the bubbling behavior was recorded using a camera from the top of the slag. Since the height of the oxide phase in the molten metal bath was small, the temperature of gas bubble is assumed to be room temperature. Hence, the volume and equivalent radius of the gas bubble were estimated by determining the frequency of rupture, through Eqs. (1) and (2), respectively.
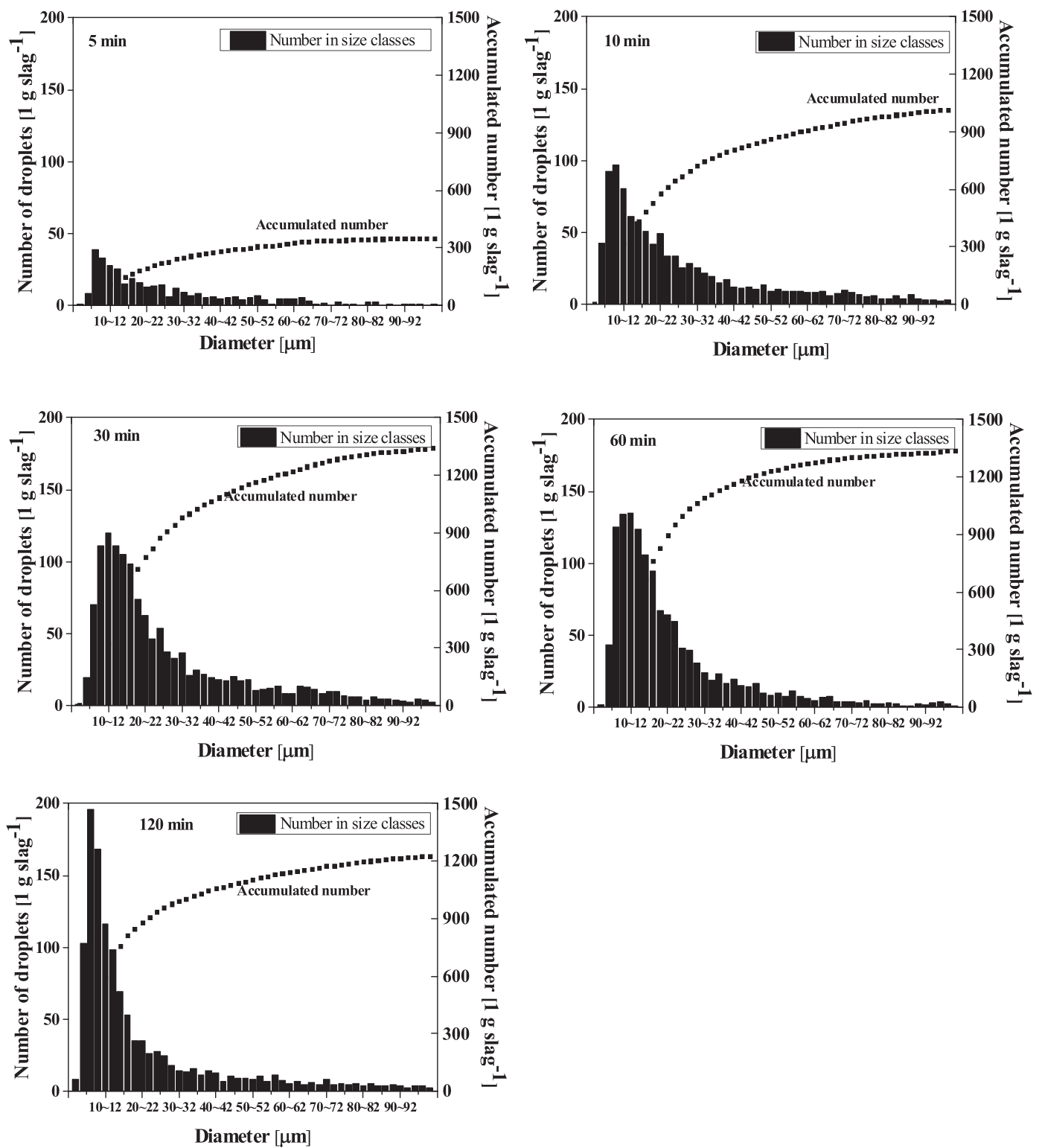

Fig. 2. Time dependence of size distribution of metal droplets in $1 \mathrm{~g}$ slag at $300 \mathrm{NmL} / \mathrm{min}$. 


$$
\begin{gathered}
V_{b}=1 \times 10^{-6} \frac{Q}{F} \ldots \\
R=0.01 \times \sqrt[3]{\frac{3 Q}{4 \pi F}} .
\end{gathered}
$$

where $V_{b}$ is the volume of the gas bubble $\left[\mathrm{m}^{3}\right], R$ is the radius of the gas bubble [m], $Q$ is the gas flow rate $[\mathrm{NmL} / \mathrm{min}]$, and $F$ is the frequency of rupture of the gas bubble [ $\mathrm{min}^{-1}$.

\section{Results}

Figure 2 shows the number of metal droplets in different size ranges and the total number of droplets with diameter smaller than each size at a gas flow rate of $300 \mathrm{NmL} / \mathrm{min}$ during bubbling. The total number increased with time and became almost constant after $30 \mathrm{~min}$. This trend was also observed at the other gas flow rates. Furthermore, it was observed that a majority of the metal droplets were less than $30 \mu \mathrm{m}$ in diameter, and droplets with diameters in the range of 6-12 $\mu \mathrm{m}$ were the largest in number. Droplets larger than $40 \mu \mathrm{m}$ were observed from 5 min onward, and they showed a similar distribution after $10 \mathrm{~min}$. Figure 3 shows the size distribution of metal droplets for each gas flow rate at $120 \mathrm{~min}$ in comparison to that in the Sn alloy/chloride system. ${ }^{3)}$ No clear difference was found in the size distribution between the two systems at a gas flow rate lower than $50 \mathrm{NmL} / \mathrm{min}$, and approximately $80 \%$ of the total droplets were observed to have diameters in the range of $2-10 \mu \mathrm{m}$. Droplets larger than $30 \mu \mathrm{m}$ were rarely observed in both the systems. At gas flow rates higher than $100 \mathrm{NmL} / \mathrm{min}$, an increase in the number of droplets with diameters of less than $30 \mu \mathrm{m}$ was observed in both the systems; this number in the chloride system was larger than that in the oxide system. This difference became larger with an increase in the gas flow rate, and at $500 \mathrm{NmL} / \mathrm{min}$, approximately 10000 droplets were observed in the chloride system, which was nearly 6 times that in the oxide system. On the other hand, several metal droplets larger than $30 \mu \mathrm{m}$ were observed in the oxide system. The number of large metal droplets was evenly distributed between $30 \mu \mathrm{m}$ and $100 \mu \mathrm{m}$. In the chloride system, large droplets were not observed even at a high
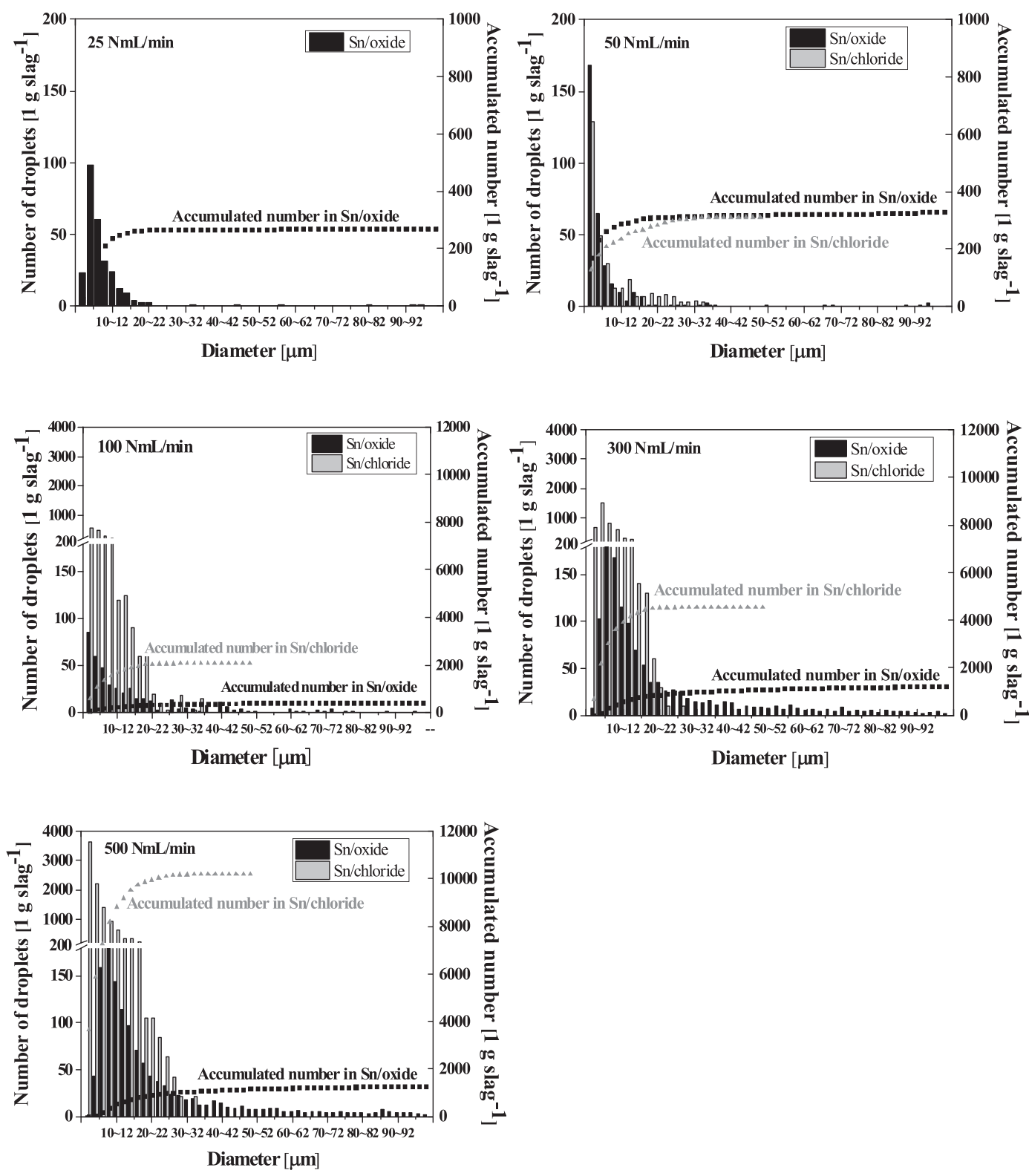

Fig. 3. Size distribution of metal droplets in $1 \mathrm{~g}$ slag at $120 \mathrm{~min}$ at various gas flow rates. 
gas flow rate. Figure 4 shows the size distribution of the droplets after the termination of gas bubbling at $100 \mathrm{NmL} /$ min. The total number of droplets decreased gradually with time, but droplets of $50 \mu \mathrm{m}$ or larger disappeared rapidly. After $30 \mathrm{~min}$, few large droplets were found in the oxide phase. However, many small droplets of less than $20 \mu \mathrm{m}$ remained in the oxide even after $120 \mathrm{~min}$.

The time dependence of the total mass of metal droplets during bubbling at various gas flow rates is summarized in Fig. 5. The mass (M, g/1 g slag) of metal droplets was derived using Eq. (3).

$$
M=\frac{4 \pi \rho_{m} \sum_{i=1}^{n} r_{i}^{3}}{3 m}
$$

where $r_{i}$ is the radius of metal droplets [m], $m$ is the mass of the sampled oxide [kg], and $\rho_{m}$ is the density of the $\mathrm{Sn}$ alloy $\left[\mathrm{kg} / \mathrm{m}^{3}\right]$.

It was seen that the total mass of metal droplets increased with time and attained a stable state. As the gas flow rate increased, the time to attain the stable state became shorter.
In addition, after the stable state was attained, the total mass of metal droplets increased with an increase in the gas flow rate. The change in the total mass of droplets with time after the termination of bubbling is shown in Fig. 6. Clearly, the

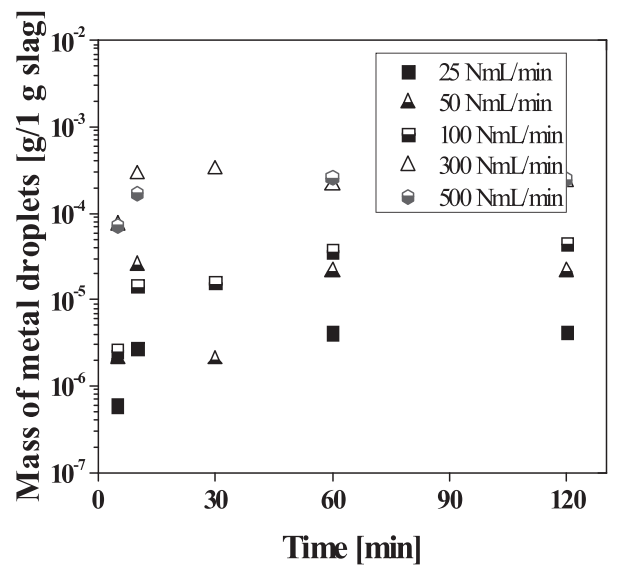

Fig. 5. Time dependence of metal droplet mass during bubbling at various gas flow rates.
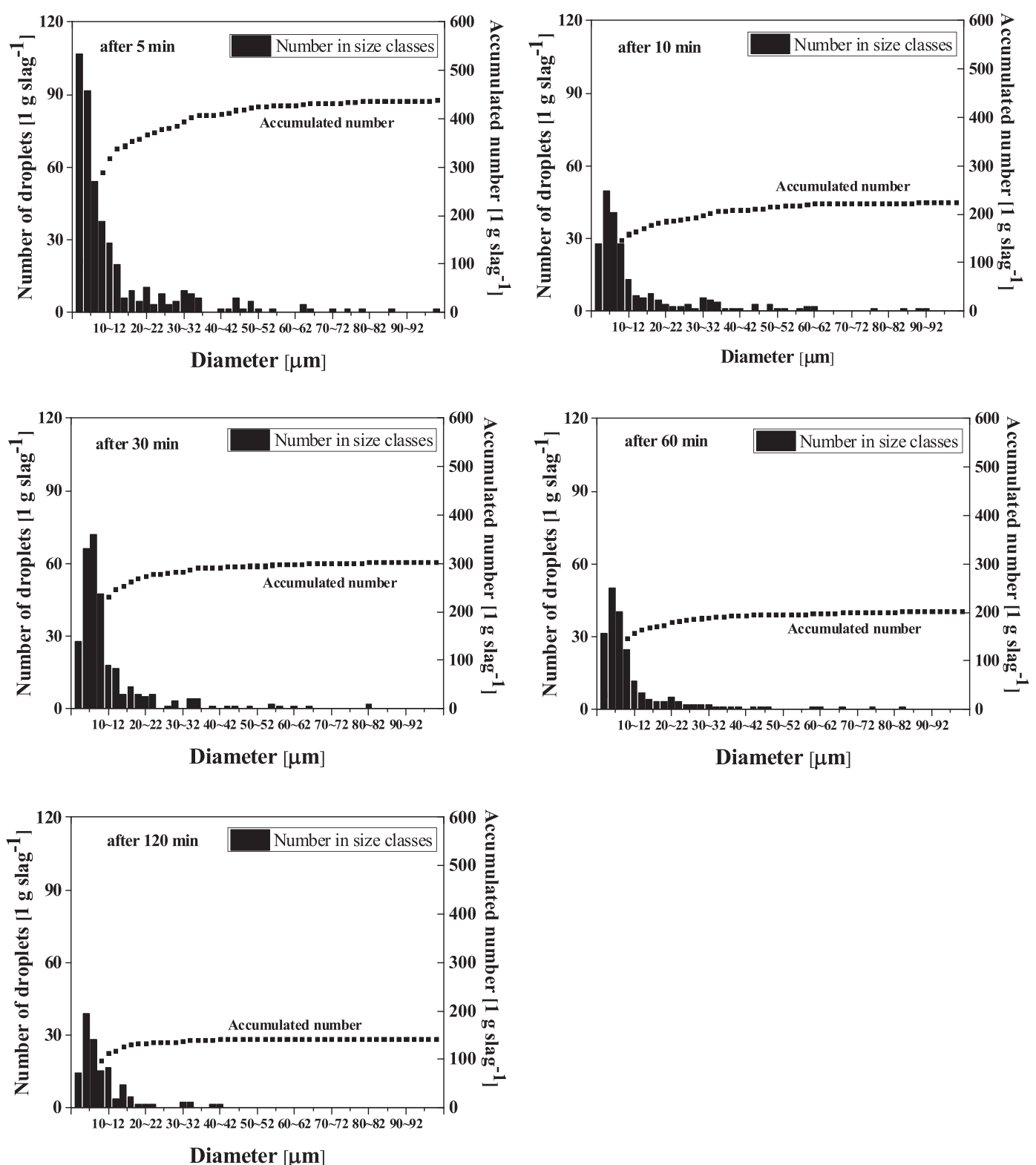

Fig. 4. Time dependence of size distribution of metal droplets in $1 \mathrm{~g}$ slag after termination of gas bubbling. 
total mass decreased continuously with time in spite of the presence of some tiny droplets. The total mass after bubbling at $100 \mathrm{NmL} / \mathrm{min}$ was larger than that at $50 \mathrm{NmL} / \mathrm{min}$ even at $30 \mathrm{~min}$ or later, since many metal droplets smaller than $20 \mu \mathrm{m}$ were formed during the bubbling at $100 \mathrm{NmL}$ / min, as shown in Fig. 3.

The change in the total mass of metal droplets at steady state with the gas flow rate in comparison to that in the chloride system is shown in Fig. 7. In both the systems, the total mass increased with an increase in the gas flow rate and became almost constant when the gas flow rate reached $300 \mathrm{NmL} / \mathrm{min}$. It can be noted that the total mass in the oxide system was approximately five times that in the chloride system when the gas flow rate was higher than $300 \mathrm{NmL} / \mathrm{min}$, even though the number of droplets in the chloride system was around five times that in the oxide system, as shown in Fig. 3. This result indicates that significantly larger metal droplets dispersed in the oxide system.

The total surface area $\left[S, \mathrm{~m}^{2} / 1 \mathrm{~g}\right.$ slag $]$ of the metal droplets was determined using the following equation:

$$
S=\frac{4 \pi \sum_{i=1}^{n} r_{i}^{2}}{1000 m}
$$

In both the systems, the total surface area increased with an increase in the gas flow rate, as shown in Fig. 8. At low

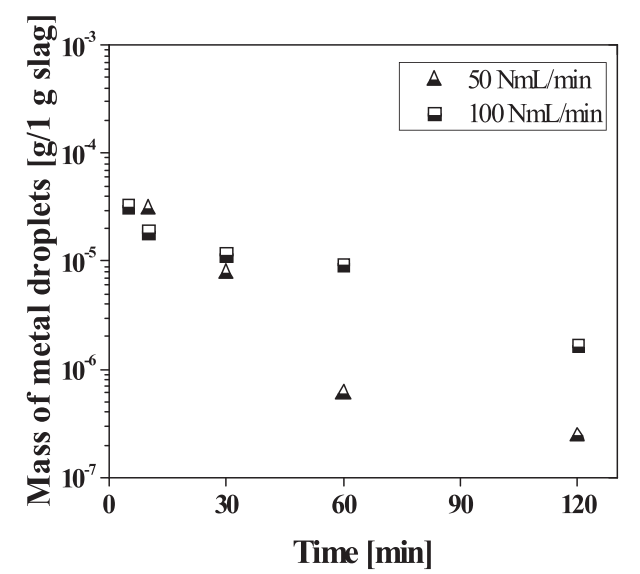

Fig. 6. Time dependence of metal droplet mass after termination of gas bubbling.

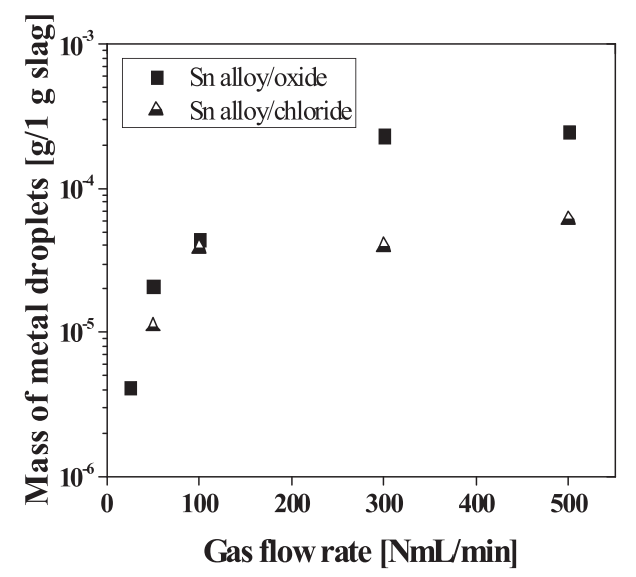

Fig. 7. Total mass of metal droplets at steady state after start of bubbling. gas flow rates, the total surface area in the chloride system was larger than that in the oxide system and it increased with increasing gas flow rate. The difference in the total surface area between the two systems became smaller and almost disappeared at $500 \mathrm{NmL} / \mathrm{min}$.

The Sauter diameter $\left[d_{32}, \mu \mathrm{m}\right]$, which is the ratio of the volume-equivalent diameter to the square of the surfaceequivalent diameter, is frequently used to describe the average size of particles, and it is calculated using Eq. (5). The Sauter diameter is inversely proportional to the surface density (surface area per unit volume). ${ }^{20)}$

$$
d_{32}=\frac{\sum\left(n_{i} d_{i}^{3}\right)}{\sum\left(n_{i} d_{i}^{2}\right)}
$$

Here, $d_{i}$ is the diameter of metal droplets [m] and $n_{i}$ is the number of droplets with diameter $d_{i}$.

The Sauter diameter of the metal droplets at steady state after the start of bubbling is shown in Fig. 9. The Sauter diameter in the oxide system was much larger than that in the chloride system, and it did not change much with a change in the gas flow rate, except at $25 \mathrm{NmL} / \mathrm{min}$ in the oxide system.

In this study, the volume of a gas bubble was calculated using Eq. (1). For comparison, the volume of a gas bubble in the chloride system was also estimated using Eq. (1), where the frequency of gas bubbles passing through the

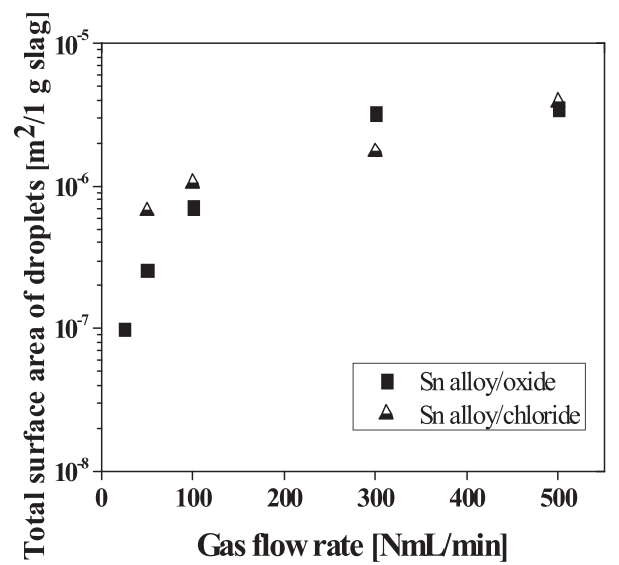

Fig. 8. Total surface area of metal droplets at steady state after start of bubbling.

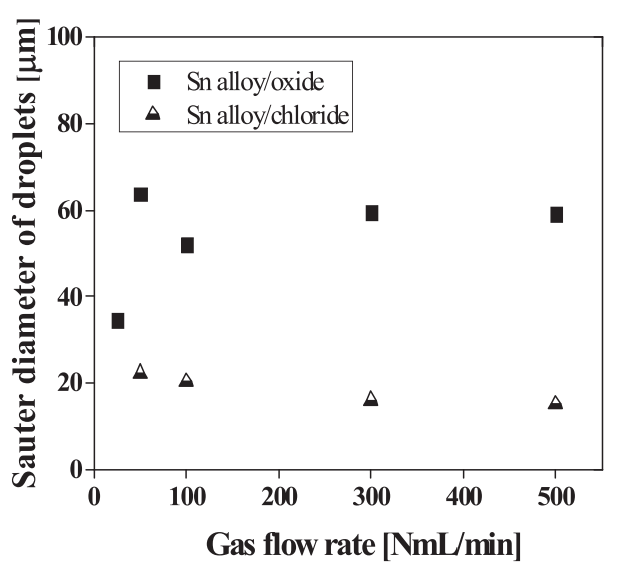

Fig. 9. Gas flow rate dependence of Sauter diameter of metal droplets at steady state. 
interface was determined by direct observation using a high-speed camera. ${ }^{3)}$ From Fig. 10, it is clear that for both the systems, the volume increased in proportion to the gas flow rate, but the gas bubbles were relatively smaller in the chloride system. The volume of gas bubble is influenced by the physical properties of system, especially the viscosity of slag phase. ${ }^{21)}$ Therefore, this difference would be caused by the high viscosity of slag. When the gas flow rate increased to $300 \mathrm{NmL} / \mathrm{min}$ and higher, the difference in the gas bubble volume between the two systems became more marked.

\section{Discussion}

\subsection{Size of Metal Droplets}

Reiter and Schwerdtfeger ${ }^{7)}$ proposed a dimensionless parameter that expresses the average relative droplet size $\left[r_{d}{ }^{*}\right]$, which is expressed as the ratio of the droplet size to the gas bubble size. In the present study, a new equation was established by employing this concept. In this equation, the ratio of the Sauter diameter of the droplets to the gas bubble diameter - which was calculated from the volume of the gas bubble by assuming its shape to be spherical — was used as the average relative droplet size. In addition to the equation of Reiter and Schwerdtfeger, the ratio of the viscosity of the upper phase to that of the lower phase was taken into account, also the ratios of the interfacial tensions and densities of the upper phase and lower phases were considered. The bubble Eötvös number [Eo] was also used, which characterizes the shape of a bubble moving in a surrounding fluid. Equation 6 was obtained by regression analysis using the results of the oxide and chloride systems:

$$
r_{d}^{*}=\frac{d_{32}}{2 \times 10^{6} R}=0.02\left(\frac{\gamma_{m s}}{\sigma_{m}}\right)^{11}\left(\frac{\rho_{s}}{\rho_{m}}\right)^{1.2}\left(\frac{\mu_{s}}{\mu_{m}}\right)^{0.15}(E o)^{-0.41}
$$

where $R$ is the radius of the gas bubble obtained by Eq. (2); $\gamma_{m s}$ is the interfacial tension between the upper and lower phases $[\mathrm{N} / \mathrm{m}] ; \sigma_{m}$ is the surface tension of the lower phase $[\mathrm{N} / \mathrm{m}] ; \rho_{s}$ and $\rho_{m}$ are the densities of the upper and lower phases, respectively $\left[\mathrm{kg} / \mathrm{m}^{3}\right]$; and $\mu_{s}$ and $\mu_{m}$ are the viscosities of the upper and lower phases, respectively $[\mathrm{Pa} \cdot \mathrm{s}]$. The Eötvös number was calculated by the following equation:

$$
E o=\frac{4 g\left(\rho_{m}-\rho_{s}\right) R^{2}}{\gamma_{m s}}
$$

Figure 11 shows a comparison between the experimen-

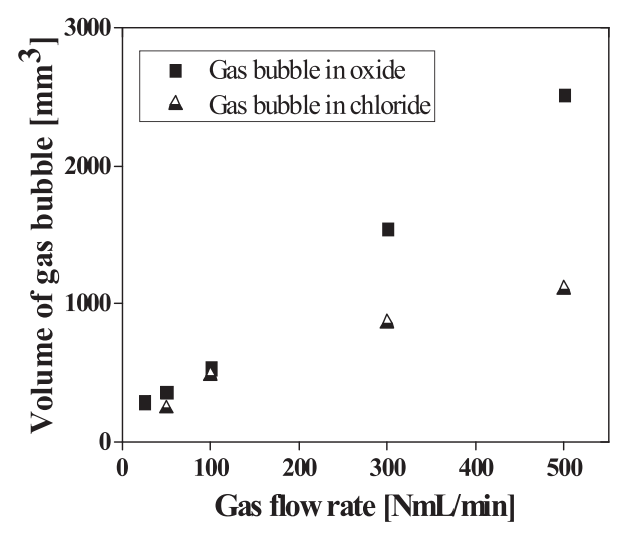

Fig. 10. Volume of gas bubble. tally observed relative diameters and the values obtained from Eq. (6). The droplets in the oxide system were larger than those in the chloride system owing to the gas bubbles being larger in the former system, as shown in Fig. 10. In addition, Table 2 lists the values of each term of Eq. (6) for the oxide and chloride systems. ${ }^{3,14-19,22-25)}$ It was clear that the difference in the parameter $\left(\mu_{\mathrm{s}} / \mu_{\mathrm{m}}\right)^{0.15}$ between the two systems was much larger than the difference in other parameters. Therefore, the difference in the viscosity of the upper phase between the two systems might be the key factor governing he difference in the droplet size between the systems.

\subsection{Formation and Sedimentation Rates}

In a previous study, Song ${ }^{3)}$ analyzed the droplet formation rate $\left[v_{f}, \mathrm{~g} / \mathrm{min}\right]$ and sedimentation rate $\left[v_{s}, \mathrm{~g} / \mathrm{min}\right]$ separately by assuming that the formation rate is constant under the same gas flow rate and the sedimentation rate is proportional to the total mass of emulsified droplets, ${ }^{8)}$ as shown in Eqs. (8) and (9).

$$
\begin{aligned}
v_{f} & =\text { const } . . . . \\
v_{s}(t) & =C \times M(t)
\end{aligned}
$$

where $C[1 / \mathrm{min}]$ is the sedimentation coefficient, $M(t)$ is the total mass of metal droplets at each time in $1 \mathrm{~g}$ of the upper phase [g], and $t$ is the time after the start of bubbling [min].

The observed accumulation rate $\left[v_{a}, \mathrm{~g} / \mathrm{min}\right]$ is the difference between the formation rate and the sedimentation rate described by Eqs. (8) and (9), respectively.

$$
v_{a}=v_{f}-v_{s}=v_{f}-C \times M(t) .
$$

By integration of this equation, the mass of metal droplets is expressed as in Eq. (11):

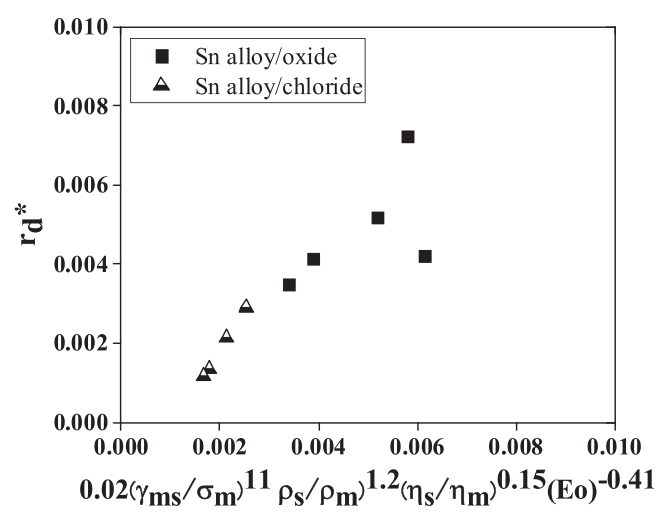

Fig. 11. Dimensionless analysis of effects of experimental conditions on droplet diameter.

Table 2. Comparison of each parameter (interfacial tension ratio, density ratio, viscosity ratio, and Eo) in different systems at $300 \mathrm{NmL} / \mathrm{min}$.

\begin{tabular}{ccccc}
\hline System (lower/upper) & $\left(\frac{\gamma_{m s}}{\sigma_{m}}\right)^{11}$ & $\left(\frac{\rho_{s}}{\rho_{m}}\right)^{1.2}$ & $\left(\frac{\mu_{s}}{\mu_{m}}\right)^{0.15}$ & $(\mathrm{Eo})^{-0.41}$ \\
\hline Sn alloy/ $\mathrm{Na}_{2} \mathrm{~B}_{4} \mathrm{O}_{7}$ & 0.84 & 0.252 & 2.94 & 0.31 \\
Sn alloy/Chloride & 1.38 & 0.168 & 1.11 & 0.34 \\
Actual process (steel/slag) & $\approx 0.3$ & $\approx 0.299$ & $1.428-2.620$ & $\approx 0.632$
\end{tabular}




$$
M(t)=\left(1-e^{-C t}\right) \frac{v_{f}}{C}
$$

When $\mathrm{t}=\infty$, the mass is described by Eq. (12):

$$
M_{\propto}=\frac{v_{f}}{C}
$$

$M_{\propto}$ corresponds to the total mass of metal droplets at steady state, and its value $120 \mathrm{~min}$ after the start of bubbling can be used.

By substitution of Eq. (12) into Eq. (11), the mass of droplets at each time can be calculated according to Eq. (13):

$$
M(t)=\left(1-e^{-C t}\right) M_{\propto}
$$

The sedimentation coefficient can be obtained by Eq. (13) by using experimental results. Then, the formation rate can be calculated by Eq. (12). The results of the oxide system in comparison to those of the chloride system are shown in Fig. 12. ${ }^{3)}$ In each system, the formation rate increased with an increase in the gas flow rate, but when the gas flow rate increased to $300 \mathrm{NmL} / \mathrm{min}$ or higher, the formation rate in the oxide system became larger than that in the chloride system.

The total mass of metal droplets formed by a single gas bubble $\left[M_{d}, \mathrm{~g}\right]$ is calculated by Eq. (14).

$$
M_{d}=\frac{v_{f}}{F}
$$

As shown in Fig. 13, in both the systems, the total mass of metal droplets formed by a single gas bubble increased with an increase in the gas bubble volume, which implies that larger gas bubbles formed a higher number of droplets in the upper phase. However, when the bubble volume was small, the mass of droplets per bubble in the chloride system was larger than that in the oxide system.

In general, metal droplets were formed by the disintegration of a metal film or metal column. A metal film was formed by the passage of gas bubbles through the interface. As the bubble entered the upper phase, it became thinner, and at a certain thickness, it disintegrated into droplets. Therefore, the total mass of metal droplets depended on the film surface area $\left[A, \mathrm{~m}^{2}\right]$ and thickness $\left[T_{f}, \mathrm{~m}\right]$ just before rupture. Kobayashi proposed Eq. (15) to calculate the film surface area based on the balance between the buoyancy

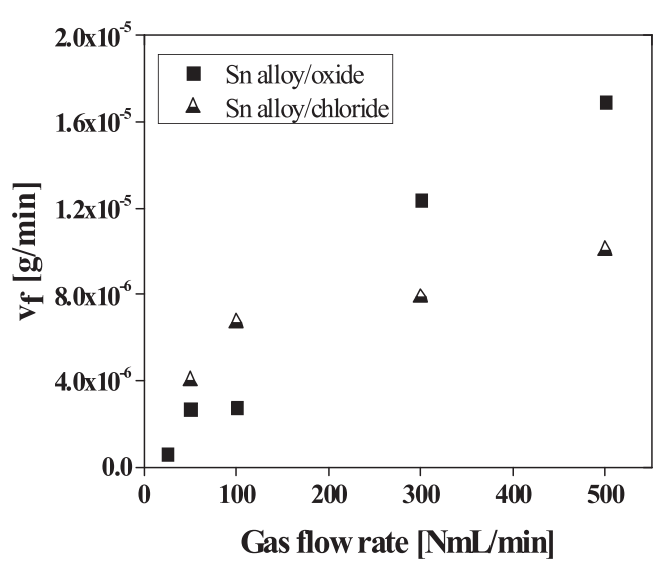

Fig. 12. Formation rate of metal droplets at various gas flow rates. force and the vertical component of the interfacial tension. ${ }^{26)}$ In addition, the change in the thickness of the liquid film with time $\left[u_{T}, \mathrm{~m} / \mathrm{s}\right]$ was estimated by Eq. (16). ${ }^{27)}$

$$
\begin{gathered}
\mathrm{A}=\frac{4\left(\rho_{m}-\rho_{s}\right) \mathrm{g} \pi}{3\left(\gamma_{m s}+\sigma_{m}\right)} R^{4} . \\
u_{T}=-\frac{d T_{f}}{d T}=\frac{2 \pi F_{g}}{3 \mu_{s} A^{2}} T_{f}^{3} .
\end{gathered}
$$

Here, $F_{g}[\mathrm{~N}]$ is the buoyancy force of the gas bubble, which is calculated by Eq. (17). Considering that $\rho_{\mathrm{m}} \gg \rho_{\mathrm{g}}$, the thickness of the film was described by Eqs. (18) and (19) by the integration of Eq. (16). ${ }^{26)}$

$$
\begin{gathered}
F_{g}=\frac{4}{3} \pi R^{3} g\left(\rho_{m}-\rho_{g}\right) \\
T_{f}=(2 \mathrm{a} T+x)^{-\frac{1}{2}} \ldots \ldots \\
a=\frac{\left(\gamma_{m s}+\sigma_{m}\right)^{2}}{2 \mu_{m}\left(\rho_{m}-\rho_{s}\right) \mathrm{g} R^{5}}
\end{gathered}
$$

Here, $T$ is the time from the arrival of the gas bubble at the interface until its detachment $[\mathrm{s}], \rho_{g}$ is the density of gas in the bubble $\left[\mathrm{kg} / \mathrm{m}^{3}\right]$, and $x$ is a constant derived from experimental results.

From Eq. (15), it is found that the film surface area is determined mainly by the bubble size and that the influence of physical properties of the system on the film surface area is relatively small, as its values for the oxide and chloride systems are not very different. In addition, parameter $a$ is determined mainly by the bubble size and the value of $\boldsymbol{T}$ decreases with an increase in the bubble size. ${ }^{28)}$ As is known from Eq. (18), the thickness of the film decreases with an increase in $\boldsymbol{a}$ and $\boldsymbol{T}$. This implies that when a large gas bubble reaches the interface, it can lift a much larger and thicker metal film and form more metal droplets. In other cases, during the rise of a bubble in the upper phase, the columnar metal phase is attached in the wake of the bubble, and the metals droplets form at a certain height by the disintegration of this column. In this study, the metal column was found to have been formed when the gas bubble was larger than a certain critical size. With an increase in the size of the gas bubble, the formation frequency of the

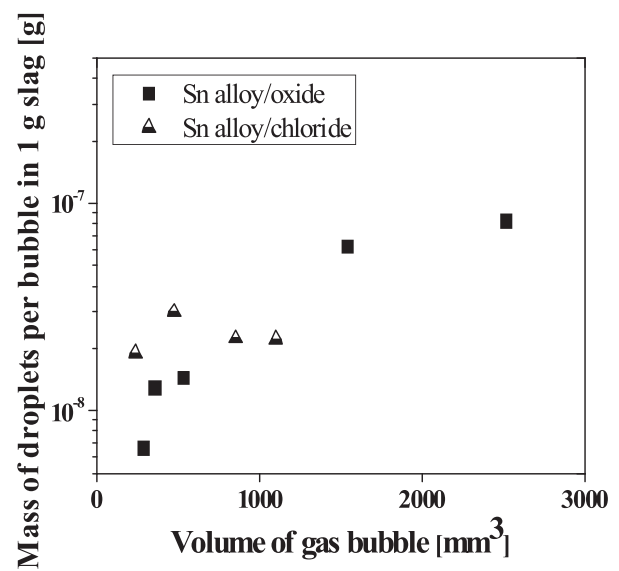

Fig. 13. Formation rate of metal droplets by single gas bubble. 
metal column increased. ${ }^{14)}$ Therefore, by this mechanism, as the gas bubble size increases, the mass of metal droplets formed by a single gas bubble increases. These mechanisms would support our result that the total mass of metal droplets formed by a single gas bubble increased with an increase in the gas bubble volume in both the systems, as shown in Fig. 13.

Han and Holappa measured metal entrainment into a molten iron/slag system and found that a low viscosity of the upper phase was favorable for transporting the metal phase into the upper phase. $\left.{ }^{9}\right)$ Reiter and Lin found that a high viscosity of the upper phase had a negative effect on the formation of metal droplets by a single gas bubble. ${ }^{7,8)}$ In the present study, when the gas bubble volume was smaller than $1000 \mathrm{~mm}^{3}$, the total mass of droplets in the oxide system was smaller than that in the chloride system, as shown in Fig. 13. This should have been caused by the high viscosity of the upper phase. However, when the bubble size increased, the difference in the total mass of droplets between the oxide and chloride systems was unclear because of the large difference in the bubble size between these systems. Clarification of the influence of viscosity on droplet formation by large-sized bubbles is an important research topic in the future.

A comparison of the sedimentation coefficients of the two systems is shown in Fig. 14. It is clear that the sedimentation coefficient of the oxide system is smaller than that of the chloride system, especially under the condition of higher gas flow rates. The sedimentation coefficient can be used to describe the sedimentation potential of metal droplets, and it is determined by the metal droplets size and physical properties of upper phase. Comparing with the two systems, although the average droplets size is larger in $\mathrm{Sn} / \mathrm{slag}$ system, its sedimentation coefficient is smaller. Therefore, the difference in the slag viscosity had rather larger influence than that in the metal droplets size.

From the sedimentation coefficient, the sedimentation rate during bubbling in the oxide system can be calculated using Eq. (9). On the other hand, the sedimentation rate after the termination of gas bubbling can be determined using the results shown in Fig. 6. Figure 15 shows the relation between the total mass of droplets and the sedimentation rate in the oxide system in comparison to that in the chloride system. It is confirmed that in both the systems, the

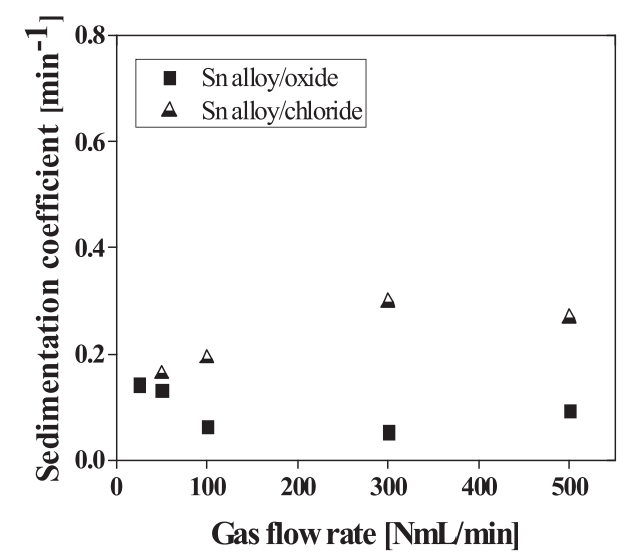

Fig. 14. Sedimentation coefficient of droplets at various gas flow rates. sedimentation rate increased in proportion to the total mass of droplets in the upper phases after the termination of gas bubbling, and the sedimentation rate in the chloride system was larger than that in the oxide system. No clear difference was found between the sedimentation rate observed after the termination of bubbling and that calculated during the bubbling. This implies that the fluid flow in the slag phase has a negligible effect on the sedimentation rate of the metal droplets under the experimental condition. The difference between the sedimentation rates in the two systems arises from the difference in the viscosities of their upper phases.

The descending rate of the droplet is determined by balancing the gravity force (Eq. (20)), the added mass force (Eq. (21)), the buoyancy force (Eq. (22)), and the viscous drag force (Eq. (23)). ${ }^{29)}$ The latter two forces can be considered as a resistance force. They are affected by the physical properties and the fluid convection condition. The total force in the downward direction $[F, \mathrm{~N}]$ is described by Eq. (24).

$$
\begin{gathered}
F_{G}=\frac{4 \pi}{3} r_{i}^{3} \rho_{m} g \ldots . . \\
F_{A}=\frac{2 \pi}{3} r_{i}^{3} \rho_{s} \frac{d u_{d}}{d t} \ldots \\
F_{B}=\frac{4 \pi}{3} r_{i}^{3} \rho_{s} g \ldots \ldots \\
F_{D}=C_{D} \cdot \frac{1}{2} \rho_{s} u_{d}^{2} \cdot \pi r_{i}^{2} \\
F=F_{G}+F_{A}-F_{B}-F_{D} \\
\frac{d u_{d}}{d t}=\frac{F}{\frac{4 \pi}{3} r_{i}^{3} \rho_{m}} \ldots . .
\end{gathered}
$$

The total force can be obtained by integration, as given in Eq. (26):

$$
F=\frac{2 \rho_{m}\left(F_{G}-F_{B}-F_{D}\right)}{2 \rho_{m}-\rho_{s}}
$$

where $u_{d}$ is the descending velocity of metal droplets in the slag phase $[\mathrm{m} / \mathrm{s}]$. Under this experimental condition, the Reynolds Number (Eq. (27)) is in the range of $1 \times$ $10^{-3}-2 \times 10^{-1}$ with the assumption that the velocity of the

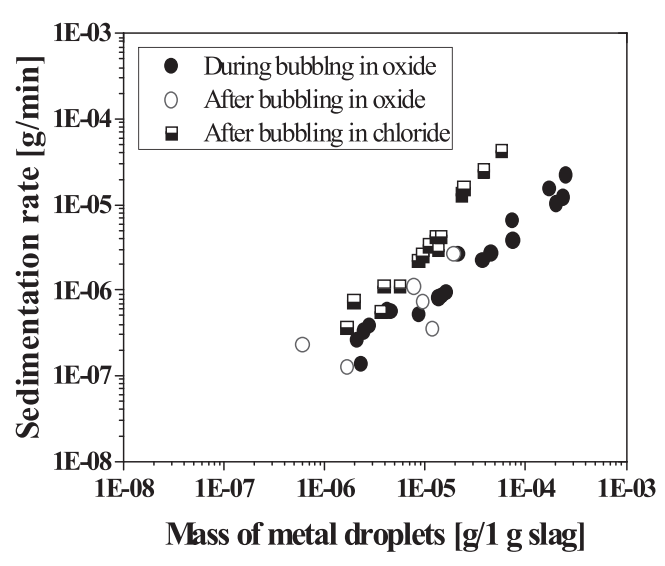

Fig. 15. Sedimentation rate of droplets. 


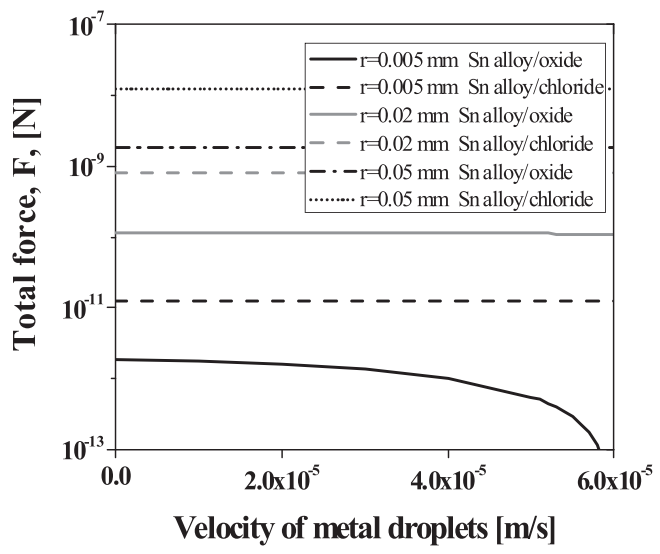

Fig. 16. Total force on metal droplets.

fluid $\left[v_{m}, \mathrm{~m} / \mathrm{s}\right]$ is close to the terminal velocity of the gas bubble. ${ }^{30)}$ Then, the drag coefficient $C_{D}$ in Eq. (23) can be expressed as in Eq. (29).

$$
\begin{gathered}
R e=\frac{\rho_{s} v_{m} d_{i}}{\mu_{s}} \ldots \\
v_{m}=1.02 \sqrt{g R} \\
C_{D}=\frac{24}{R e} \ldots .
\end{gathered}
$$

Figure 16 shows the total force acting on metal droplets of different sizes during bubbling at $300 \mathrm{NmL} / \mathrm{min}$. As the viscosity of the oxide was approximately 400 times that of the chloride, the viscous drag in the oxide system was much larger than that in the chloride system. For all droplet sizes, the total force on the metal droplets in the chloride system was larger than that in the oxide system. As a result, the sedimentation rate in the oxide system became smaller than that in the chloride system, as shown in Fig. 15.

\section{Conclusion}

This study investigated the phenomenon of formation of a metal emulsion by rising gas bubbles by employing a molten $\mathrm{Sn}$ alloy/ $\mathrm{Na}_{2} \mathrm{~B}_{4} \mathrm{O}_{7}$ system, which possesses physical properties similar to those of an actual steel/slag system. Experimental samples were extracted from the molten slag. The emulsified droplets ( $<100 \mu \mathrm{m}$ in diameter) were separated and measured. The following are the key findings of the study obtained through a comparison of the results of the molten $\mathrm{Sn}$ alloy $/ \mathrm{Na}_{2} \mathrm{~B}_{4} \mathrm{O}_{7}$ system with those of a previously investigated $\mathrm{Sn}$ alloy/chloride system.

(1) In both the systems, the number of metal droplets increased with an increase in the gas flow rate, but the number of metal droplets in the chloride system was much larger than that in the oxide system under the high gas flow rate condition. In addition, in the oxide system, many large-sized droplets $30 \mu \mathrm{m}$ or larger in size were observed, which were rarely observed in the chloride system.

(2) In both the systems, the total mass of metal droplets increased with an increase in the gas flow rate, and at gas flow rates higher than $300 \mathrm{NmL} / \mathrm{min}$, the total mass of metal droplets in the oxide system was five times that in the chloride system. In both the systems, the total surface area of the droplets increased with an increase in the gas flow rate; however, the difference in the total surface area between the two systems was small.

(3) In both the systems, the equivalent diameter of the gas bubble increased with an increase in the gas flow rate, and it was larger in the oxide system than in the chloride system.

(4) In both the systems, the average size of the emulsified droplets was constant when the gas flow rate was higher than $50 \mathrm{NmL} / \mathrm{min}$, but it was much larger in the oxide system than in the chloride system.

(5) In both the systems, the total mass of droplets formed by a single bubble increased with an increase in the gas flow rate, and this total mass in the chloride system was greater than that in the oxide system when the volume of the gas bubble was smaller than $1000 \mathrm{~mm}^{3}$. The sedimentation rate in the oxide system was lower than that in the chloride system.

\section{Acknowledgements}

The authors would like to gratefully acknowledge the financial support provided by Nippon Steel \& Sumitomo Metal Corporation and the helpful discussions with Dr. Yuji Ogawa and Mr. Shinpei Ono. The authors profoundly thank Professor Hiroshi Nogami and Professor Piotr R. Scheller for the valuable inputs provided through discussions.

\section{REFERENCES}

1) K. Horii, N. Tsutsusumi, Y. Kitano and T. Kato: Nippon Steel Tech. Rep., (2013), No. 104, 122.

2) A. I. V. Dana, M. M. Carmen, B. Liviu, A. Claudiu, B. Anca and C. Nicoleta: Proc. 7th Int. Conf. Interdisciplinarity in Engineering, Elsevier, Amsterdam, (2013), 615.

3) D. Y. Song: Ph.D. thesis, Tohoku University, Sendai, (2012).

4) G. Reiter and K. Schwerdtfeger: ISIJ Int., 32 (1992), 50.

5) R. Minto and W. G. Davenport: Can. Min. Metal. Bull., 65 (1972), 70 .

6) Z. Han and L. Holappa: ISIJ Int., 43 (2003), 292

7) G. Reiter and K. Schwerdtfeger: ISIJ Int., 32 (1992), 57.

8) Z. H. Lin and R. I. L. Guthrir: Metall. Mater. Trans. B, 25B (1994), 855 .

9) Z. Han and L. Holappa: Metall. Mater. Trans. B, 34 (2003), 525.

10) D. Poggi, R. Minto and W. G. Davenport: J. Met., 21 (1969), 40.

11) D. Y. Song, N. Maruoka, T. Maeyama, H. Shibata and S. Kitamura: ISIJ Int., 50 (2010), 1539.

12) D. Y. Song, N. Maruoka, G. S. Gupta, H. Shibata, S. Kitamura, N. Sasaki, Y. Ogawa and M. Matsuo: ISIJ Int., 52 (2012), 1018.

13) N. Maruoka, D. Y. Song, G. S. Gupta, H. Shibata and S. Kitamura: J. Jpn. Soc. Exp. Mech., 14 (2014), s200.

14) H. Yoshida, J. Liu, S. J. Kim, X. Gao, S. Ueda and S. Kitamura: ISIJ Int., 56 (2016), 1902.

15) J. Liu, N. Maruoka and S. Kitamura: CAMP-ISIJ, 28 (2015), 180.

16) M. Dalle Donne, S. Dorner and A. Roth: J. Nucl. Mater., 118 (1983), 195.

17) Y. Plevachuk, W. Hoyer, I. Kaban, M. Köhler and R. Novakovic: $J$. Mater. Sci., 45 (2010), 2051.

18) G. Q. Zuo: ISIJ Int., 40 (2000), 1195.

19) P. G. Jonsson, L. Jonsso and D. Sichen: ISIJ Int., 37 (1997), 484.

20) A. Zaidi and H. Y. Sohn: ISIJ Int., 35 (1995), 234.

21) Q. Wu, X. K. Wang, T. F. Wang, M. Han, Z. L. Sha and J. F. Wang: Can. J. Chem. Eng., 91 (2013), 1957.

22) J. Lee, W. Shimoda and T. Tanaka: Mater. Trans., 45 (2004), 2864.

23) K. Nakashima and K. Mori: ISIJ Int., 32 (1992), 11.

24) Z. Morita: ISIJ Int., 36 (1996), S6.

25) Y. Ogawa, D. Huin, H. Gaye and N. Tokumitsu: ISIJ Int., 33 (1993), 224.

26) S. Kobayashi: ISIJ Int., 33 (1993), 577.

27) H. M. Princen: J. Colloid Sci., 18 (1963), 178.

28) M. Kemiha, E. Olmos, W. Fei, S. Poncin and H. Z. Li: Ind. Eng. Chem. Res., 46 (2007), 6099.

29) D. Y. Song, N. Maruoka, G. S. Gupta, H. Shibata, S. Kitamura and S. Kamble: Metall. Mater. Trans. B, 43B (2012), 973.

30) H. D. Mendelson: AIChE J., 13 (1967), 250. 